\title{
Antidiabetic Activity of Couroupita guianensis -A Review
}

\author{
Swapnalatha .S and Devi Rajeswari. V* \\ School of Biosciences and Technology, VIT University, Vellore - 632014, TN, India.
}

\begin{abstract}
Couroupita guianensis is also called as "Cannon ball tree". The tree has enormous medicinal values since most of the parts like leaves; flower, fruits and stem are used as medicine to cure various diseases. During the last few decades it has been observed that there are numerous reports on anti-inflammatory activity, antiulcer activity, anticancer activity, anti oxidant activity, antihelminthic activity of this plant. It is enriched with a number of compounds such as oils, ketosteroids, glycosides, courouptine, indirubin, isatin and phenolic substances. Recent researches on this plant extract showed anti diabetic activity also. A small preliminary test was performed to confirm its anti diabetic activity.
\end{abstract}

Key Words: Antidiabaetic, Ketosteriods, Courouptine, Indirubin, Cytotoxic, Quercetin, Kaempherol, Farmaricetin, Lutolin, Saponin.

\section{Introduction:}

Plants are the basic source of knowledge of modern medicine. Almost all the parts of the plant, namely leaves, flowers, fruits, roots, stem and seeds are known to have various medicinal properties. The trend of using natural products has increased and the active plant extracts are frequently screened for new drug discoveries. The use of the medicinal herbs for curing disease has been documented in the history. One important plant that is used in traditional medicine is Couroupita guianensis is a tree belonging to the family Lechythidaceae commonly known as Nagalinga pushpam in tamil.

Couroupita guianensis has showed a broad spectrum of anti bacterial and antifungal activities. The leaves of Couroupita guianensis yielded an aliphatic triterpene, it is used as an anti-depressant using in rats. The phenolic compounds of Couroupita guianensis are active in curing the kidney and stomach problems and helpful as anti inflammatory in action. The biological function of flavanoids, apart from their anti oxidant properties, include protection against allergies, inflammation, platelet aggregation, microbial ulcers, hepatotoxins's virus and tumours. It is known that one of the active constituents of the medicinal plant Couroupita guianensis namely isatin, is known to exert cytotoxic activity against certain cancer cell lines, being a potential source of new chemo therapeutic agents. In a study performed using extracts of Couroupita guianensis against human promylocytic leukemia(HL60) cells, isatin showed antioxidant activity and was cytotoxic to the HL60 cells due to induction of apoptosis, a natural cell death. These results suggest that isatin can be further evaluated to be used as a prophylactic agent to prevent the free radical induced cancer and as a chemotherapeutic agent to kill the cancer cells.

1. Antimicrobial activities :

II. Biological activities

The methanol and aqueous extracts of the Couroupita guianensis leaf were screened against six human pathogenic bacteria and four fungal pathogens to check antibacterial and antifungal activities by well diffusion method which showed valuable zone of inhibition. Methanol extract was better than the aqueous extract against bacteria as well as fungal pathogens. The maximum activity $(31 \mathrm{~mm})$ was recorded from 200 $\mathrm{mg}$ of methanol extract of Couroupita guianensis against Salmonella typhi followed by $29 \mathrm{~mm}$ against E.Coli and minimum against Steptococcus aureus at $50 \mathrm{mg}$ level whereas the aqueous extract showed the maximum activity $(30 \mathrm{~mm}$ ) was recorded from $200 \mathrm{mg}$ of leaf extract against E.Coli and minimum by 50 $\mathrm{mg}$ of extract against the above bacteria. Leuconostac lactis, Pseudomonas aeruginosa and Streptococcus pyogenes did not showed any activity against both the extracts.

2. Anti ulcer activities :

The anti ulcer activity in ethanolic extract of Couroupita guianensis at a dose of 150 and $300 \mathrm{mg} / \mathrm{kg}$ produced significant inhibition of the gastric lesions induced by pylorus ligation induced ulcer and ethanol induced gastric ulcer.

3. Antioxidant activity :

The alcoholic extract of Couroupita guianensis significantly stimulated the wound concentration this is due to the presence of stigmasterol and flavonoids in the extract. The results indicated that Couroupita guianensis accelerates the wound healing process by decreasing the surface area of the wound and increasing the tensile strength. 
4. Antihelminthic activity :

Study tested the activity of chloroform, acetone and ethanolic flower extracts of Couroupita guianensis for antihelminthic activity against adult earthworm, Pheritima posthuma. The alcoholic extract was the most effect in an activity comparable with piperazine citrate.

5. Anti cancer activities :

The flowers of Couroupita guianensis consists of compound isatin. The derivatives of this compound is known to have cytotoxicity against human carcinoma cell lines. This compound has a potential to be used as a chemotherapeutic agent against cancer. Isatin started the apostastis process with fragmentation of DNA. Cleavage of DNA at the inter nucleosomal linker sites yielding DNA fragments is regarded as a biochemical hallmark of apopstosis.

6. Anti fungal activity:

The activity of plant extracts on bacteria and fungi has been studied by a very large number of researches in different parts of the world. As a result, antifungal therapy is playing a greater role in health care and the screening of the traditional plants in search of novel antifungals. Due to the increasing development of drug resistance in human pathogens as well as the appearance of undesirable effects of certain antimicrobial agents, there is a need to search for new antifungal agent without toxicity and side effects. In the present study, the antifungal activities of hexane, ethyl acetate and chloroform extracts of 45 medicinal plants were investigated against dermatophytes and opportunistic pathogens. Most of the extracts inhibited more than four fungal strains, the ethyl acetate extracts inhibited large number of fungi.

7. Phytochemical analysis of fruit rind of Couroupita guianensis :

An activity was undertaken to know more about its phytochemical analysis, compound isolation, antimicrobial activity and antioxidant status to ensure its usage in pharmaceutical industries. The different solvents extracts were tested against certain pathogens, observed zone of inhibition and determined MIC. Qualitative phyto chemical observation showed main components like rutin, quercetin, kaempherol, farmaricetin, lutolin, saponin derivatives like hopanes, which have anticancer activity.

8. Analgesic activity :

Analgesic activity was evaluated using tail flick method and anti inflammatory activity was screened by measuring the reduction in carrageenan induced hind paw oedema. The potency of various extracts of flower and bark were compared with i) paracetamol $(200 \mathrm{mg} / \mathrm{kg})$ for analgesic activity. The peak analgesic effect of flower was seen after 1 hour while bark extracts showed peak effect after 2 hours. Maximum reduction in inflammation by the extracts was observed after 3 hours. They finally concluded that the plant is almost equipotent to paracetamol in its analgesic activity.

Targeted study - Anti diabetic activity:

As the above mentioned plant has shown many pharmacological activities and the only activity which is left behind was the antidiabetic activity. Homeopathic medicine has accepted the fact that the leaf extracts of the plant under study has shown positive results in inhibiting diabetics. So there came an interest to prove it in an elloborated manner.

Hence, The fresh leaves of Couroupita guianensis were collected from Shevaroy Hills, Tamilnadu and the leaves were tested for its antidiabetic activity against four bacterial strains, Escherichia coli, Pseudomonas putida, Staphylococcus aureus and Klebsiella pneumonia by agar well diffusion method and screened for Phytochemicals. The results proved that the leaf extracts showed positive results for anti diabetic activity. So it can be recommended for further studies.

Phytochemical screening of Methanolic Extract:

\begin{tabular}{|l|l|l|l|l|l|l|l|}
\hline Carbohydrates & Fixed Oils & Protein & Glycosides & Tannins & Alkaloids & Steroids & Triterpenes \\
\hline+ & - & + & + & + & + & - & - \\
\hline
\end{tabular}

\section{Results and Discussion :}

The results of the present investigation showed the antidiabetic potential of the methanol extract of the leaves of the medicinal plant Couroupita guianensis against clinical pathogens.The antidiabetic activity was found to be effective against Escherichia coli, Pseudomonas putida, Staphylococcus aureus and Klebsiella pneumonia . Moderate antimicrobial activity was recorded against E.coli (NCIM 2065), Salmonella typhi and Klebsiella pneumoniae (NCIM 2019). The crude methanol extract of the leaves of Couroupita guianensis was tested positive for the presence of Carbohydrates, Protein, Alkaloids,Terpenoids, Phenolic compounds, Reducing sugar and Triterpenoids .It was tested negative for Aminoacids, Flavonoids, Tannin, Phlobatinins, Aromatic acids and Xanthoproteins.

Moreover, in clinical fields also there is a need for novel antibiotics to compete the newly evolving multidrug resistance bacterial pathogens. The crude methanol extract of the medicinal plant Couroupita guianensis inhibited the activity of the clinical strains Staphylococcus aureus and Pseudomonas aeruginosa. In wound 
infection, Staphylococcus aureus is the predominant pathogen which delays the healing of burns and wounds. As the extract showed potential activity against Staphylococcus aureus (NCIM 5021). It can be utilized for the preparation of wound healing ointments. The phytochemical analysis of the flower extracts showed the presence of phytoconstituents such as carbohydrate, protein, alkaloids, terpenoids, phenolic compounds, reducing sugar and triterpenoids.

\section{Conclusion:}

This extensive literature survey revealed that Couroupita guianensis is an important medicinal plant with diverse pharmacological uses. The cannon ball tree possesses antimicrobial, antifungal, antiulcer, anticancer, antihelminthic and as a result of our targeted study showed antidiabetic property too. Plant based antimicrobial have enormous therapeutic potential as they can serve the human with lesser side effects and boon for the development of chemotherapy.

\section{References :}

[1]. Bauer A.W, Kirby W.M.M, Sherris J.C, Truck, M.Antimicrobial susceptibility testing by a Standardized single disk method. Am. J. Clin. Pathol. 1966.45: 493-496.

[2]. Castro SBR, Leal CAG, Freire FR, Carvelho DA, Oliveira DF,Figuiredo HCP. Antibacterial activity of plant extracts from Brazil against fish pathogenic bacteria. Brazil J Microbiol .2008.39(4):756-760.

[3]. Harbone JB. Phytochemical methods. London: Chapman and Hill. 1973.

[4]. Harborne, J.B., 1973. Phytochemical methods: a guide to modern techniques of plant analysis. London,

[5]. Chapman and Hall, Ltd, 2: 49-188.

[6]. Kokate, C. K., A. P. Purohit and S. B. Gokhale., (1995). Pharmacognosy, 3rd edition, Nirali

[7]. Prakashan, Pune.

[8]. Krishnaiah, D., T. Devi, A. Bono and R. Sarbatly, 2009. Studies on phytochemical constituents of six Malaysian medicinal plants. J. Med Plants Res, 3: 067-072

[9]. Lai PK. Antimicrobial and chemopreventive properties of herbs and spices, Curr. Med. Chem. 2004; 11: 1451-1460.

[10]. Pasquale, A. 1984. J. Ethnopharmacol., 11 (1):1-16

[11]. Pradhan D, Panda PK, and Tripathi G. Evaluation of immunomodulatory activity of methanolic extract of Couroupita guianensis Aublet. Flowers in rats. Nat Prod Rad.2009:8(1):37-42

[12]. Sanz BJ, Campos dela CJ, Epiquien RMA, Canigueral S. A first survey on the Medicinal plants of the Chazuta valley (Peruvian Amazon). J.Ethnopharmacol, 2009:122:333-362.

[13]. Sofowora, A., 1993. Recent trends in research into African medicinal plants. J. Ethnopharmacol, 38(2-3): 209-214.

[14]. Upathaya V and Pandey.Ayurvedic approach to Diabetes Mellitus and its management by Indigenous Resources. In: Diabetes Mellitus in Developing countries-Bajaj.J.S(Ed), Interprint, New Delhi. 1984: 375-377.

[15]. Visalakchi, S. and Muthumary, J. (2010). Afr. J. Microbiol. Res., 4, 38-44.

Phytochemical screening of Methanolic Extract:

\begin{tabular}{|c|c|c|c|c|c|c|c|}
\hline Carbohydrates & Fixed Oils & Protein & Glycosides & Tannins & Alkaloids & Steroids & Triterpenes \\
\hline+ & - & + & + & + & + & - & - \\
\hline
\end{tabular}

+ Presence - Absence

